\title{
Discussion of Alejano, Gonzalez and Muralha (2012)
}

\author{
S. R. Hencher
}

Received: 7 June 2012/ Accepted: 2 July 2012/Published online: 20 July 2012

(C) The Author(s) 2012. This article is published with open access at Springerlink.com

This is a useful contribution serving to illustrate the difficulties in defining a "basic friction angle" for rock joints. The fact that the authors find that the sliding angle of planar surfaces of rock in tilt tests can vary between $10^{\circ}$ and $40^{\circ}$ for a single granite block (their Fig. 12b) may come as a surprise to some engineers and researchers. Many textbooks and papers lead one to believe that there is a unique friction angle, $\emptyset_{\mathrm{b}}$, for a planar joint in "fresh" rock that can be taken as a lower bound for estimating the shear strength of natural joints empirically.

Similar variability has perplexed many authors such as Nicholson (1994) who found that friction angles for sawcut Berea sandstone in direct shear tests varied by $12.5^{\circ}$ despite great attention to sample preparation and reproducibility. Kveldsvik et al. (2008), in their investigations of the Åknes rock slope, found that the "basic friction angle" derived from tilt testing of core varied between $21^{\circ}$ and $36.4^{\circ}$.

Coulson (1971) demonstrated that the friction angle of planar surfaces of rock varies with surface finish. Krahn and Morgenstern (1979) reported similar variation for surfaces prepared in different ways and with different surface finishes. Hencher $(1976,1977)$ showed how repeated tilt testing of saw-cut and lapped rock sliders could reduce the sliding angle from over $30^{\circ}$ to almost $10^{\circ}$ after metres of displacement where rock flour was removed between runs. Continuing tests and allowing sliding debris to accumulate between runs, the sliding angle increased again. The results from two such tests using sliders of Darleydale sandstone weighted with steel blocks are

S. R. Hencher $(\bowtie)$

Halcrow China Ltd., Professor of Engineering Geology,

University of Leeds, West Yorkshire, UK

e-mail: stevehencher@btinternet.com presented in Figs. 1 and 2. Similar results were obtained using slate and limestone. All these data are valid strengths for planar rock surfaces; the sliding angle at each stage simply reflects different conditions of surface finish, wear and the presence and nature of any debris.

As Harrison (2008) noted in his review of 60 years of papers in Géotechnique: "Unfortunately, these valuable contributions seem to have been ignored by the rock mechanics community in its subsequent development of tilt tests. Furthermore, the principle that friction angle may reduce as the shear displacement continues to increase up to very large values is probably-and erroneously - not accounted for in the majority of analyses undertaken by geotechnical engineers."

The test data presented above simply illustrate that there is no single and simple "basic friction" angle for planar rock joints. Most planar rock surfaces can be roughened to the point where the friction angle approaches $40^{\circ}$; natural rock joints often have such strength even without dilation (Papaliangas et al. 1995). Much of the frictional strength is derived from ploughing and deformation of surface textural components (Engelder and Scholtz 1976). The same surfaces could be polished so that the strength reduces towards the purely adhesional contribution to friction, which, for many rocks seems to be about $10^{\circ}$.

Slopes sometimes fail at sliding angles lower than that of a saw-cut surface, which belies the concept of a lowerbound basic friction angle measurable by simple tilt tests on saw-cut or cored samples. One example investigated in detail was reported in Hencher (1982) and is summarised in Hencher (2012). Similarly the extensive, naturally polished surfaces in the Coal Measures of South Wales have been associated with large landslides. The friction angle of these natural discontinuities can be as low as $10^{\circ}$ whereas a sawcut sample through the parent rock gives more than twice 
Fig. 1 Repeated tilt tests on saw-cut and lapped sliders of Darleydale sandstone, weighted by steel blocks. For the initial runs, rock flour was allowed to accumulate

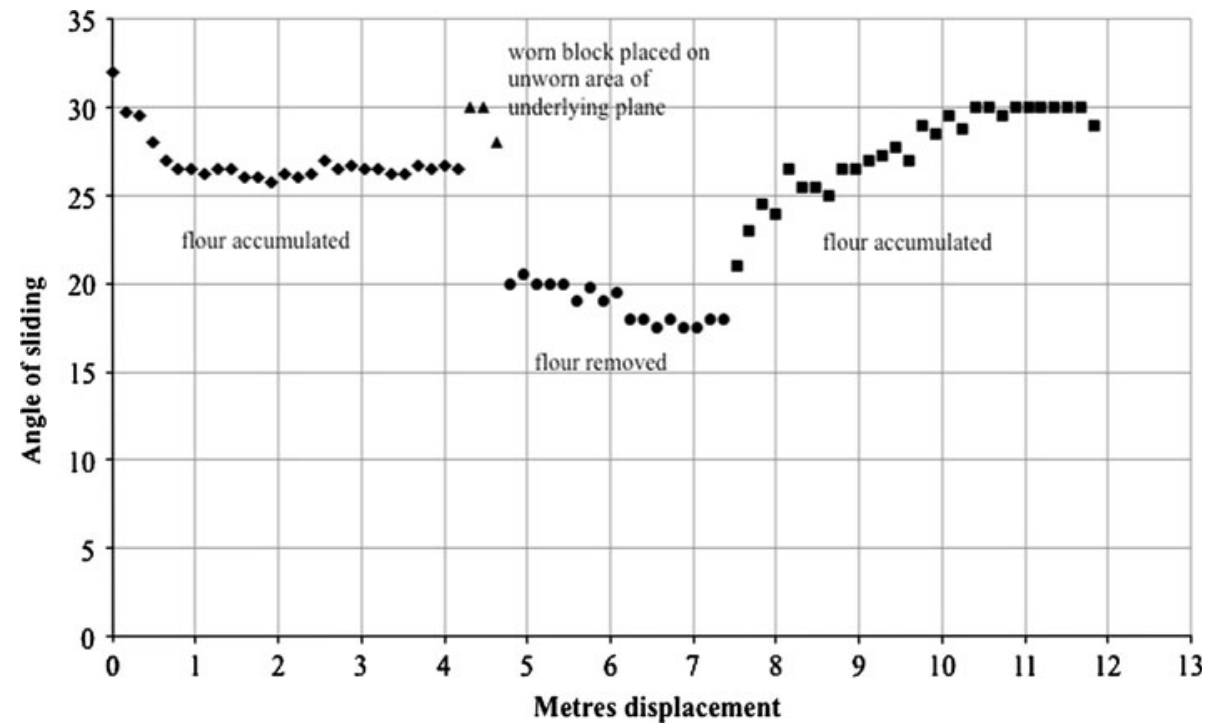

that strength (Swales 1996). A large, deep seated landslide currently being remediated in Australia (Starr et al. 2010) is sliding with an operative angle of friction of $8^{\circ}$ in mudstone which is much lower than would be anticipated from "basic friction angles" listed in Table 1 of the paper by the authors.

Finally, it should be noted that the strength for saw-cut surfaces or other artificially smoothed surfaces is usually considerably lower than the "basic" friction angle measured from direct shear tests on natural joints where corrections are made for sample-specific roughness causing dilation (Hencher and Richards 1989; Hencher 1995). Dilation-corrected data from shear tests on real joints should not be substituted as the "basic friction angle" within the Barton-Bandis model. For many rough joints, to do so would often be unsafe by perhaps $10^{\circ}$. Instead the

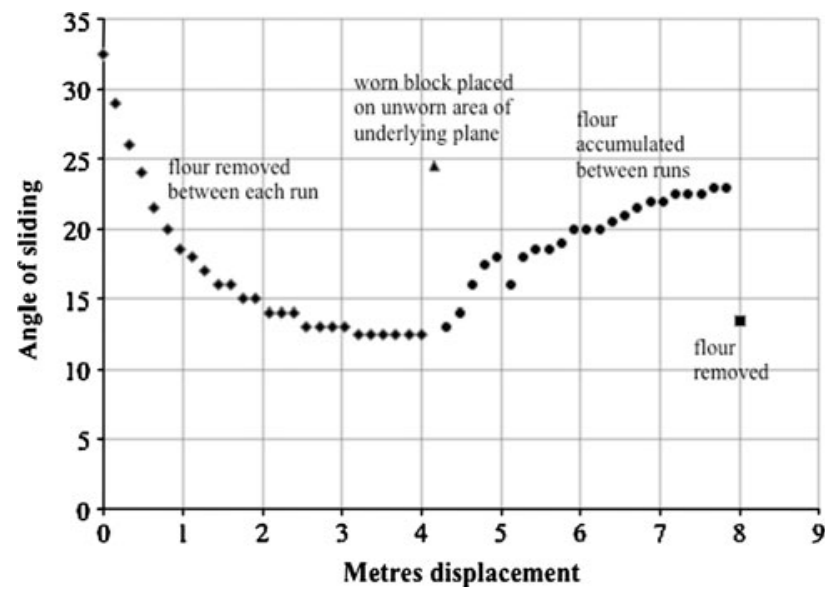

Fig. 2 Repeated tilt tests on saw-cut and lapped sliders of Darleydale sandstone, weighted by steel blocks. Between the initial runs, rock flour was removed by blowing using a lens cleaner roughness and true cohesion contributions to field strength over and above the natural, non-dilational friction need to be judged based on the field characterisation. This is discussed further in Hencher et al. (2011) and Hencher (2012).

Open Access This article is distributed under the terms of the Creative Commons Attribution License which permits any use, distribution, and reproduction in any medium, provided the original author(s) and the source are credited.

\section{References}

Coulson JH (1971) Shear strength of flat surfaces of rock. Proceedings of the 13th US symposium on Rock Mechanics, Urbana, Illinois, pp 77-105

Engelder JT, Scholtz CH (1976) The role of asperity indentation and ploughing in rock friction II. Int J Rock Mech Min Sci Geomech Abstr 13:155-163

Harrison JP (2008) Contributions to Géotechnique 1948-2008: Engineering Geology, Rock Mechanics and Rock Engineering. Géotechnique 58(5):449-455

Hencher SR (1976) A simple sliding apparatus for the measurement of rock friction. Discussion. Géotechnique 26(4):641-644

Hencher SR (1977) The Effect of Vibration on the Friction between Planar Rock Surfaces. Unpublished PhD thesis, Imperial College of Science and Technology, London University

Hencher SR (1982) Report on slope failure at Yip Kan street, Aberdeen on 12th July 1981. Unpublished Report. Geotechnical Control Office, Public Works Department, Hong Kong Government, p 26, plus 3 Appendices

Hencher SR (1995) Interpretation of direct shear tests on rock joints. In: Deaman, Schultz (eds) Proceedings 35th US Symposium on Rock Mechanics, Lake Tahoe, pp 99-106

Hencher SR (2012) Practical Engineering Geology. Taylor \& Francis, p 450

Hencher SR, Richards LR (1989) Laboratory direct shear testing of rock discontinuities. Ground Eng 22(2):24-31

Hencher SR, Lee SG, Carter TG, Richards LR (2011) Sheeting joints-characterisation, shear strength and engineering. Rock Mech Rock Eng 44:1-22 
Krahn J, Morgenstern NR (1979) The ultimate frictional resistance of rock discontinuities. Int J Rock Mech Min Sci Geomech Abstr 16:127-133

Kveldsvik V, Nilsen B, Einstein HH, Nadim F (2008) Alternative approaches for analyses of a $100,000 \mathrm{~m}^{3}$ rock slide based on Barton-Bandis shear strength criterion. Landslides 5:161-176

Nicholson GA (1994) A test is worth a thousand guesses-a paradox. In: Nelson, Laubach (eds) Proceedings of 1st NARMS Symposium, pp 523-529

Papaliangas TT, Hencher SR, Lumsden AC (1995) A comprehensive peak shear strength criterion for rock joints. In: Fuji (ed) 8th International Congress on Rock Mechanics, Tokyo, pp 359-366
Starr DC, Chenery C, Dissanayake A, McGinnis M, Woodsford J, Marks D (2010) Engineering geology of landslide at south west transport corridor, Ipswich, Queensland. In: Williams et al. (eds) Geologically Active, Taylor \& Francis Group, London, pp 85-92 Swales MJ (1996) Strength Characteristics of Potential Shear Planes in the Coal Measures Strata of South Wales. Unpublished PhD thesis, the University of Leeds 